\title{
Herpes Virus Infections
}

Daniel Mueller, M.D. and Heather Clauss, M.D.

There are nine distinct herpes viruses capable of causing infection in humans. Many clinical syndromes are associated with human herpes viruses, including cutaneous lesions, mononucleosis, retinitis, pneumonitis, and hepatitis. Hepatitis has been described in herpes simplex virus-1 (HSV-1) and HSV-2, varicella zoster virus, cytomegalovirus (CMV), Epstein-Barr virus (EBV), and human herpes virus-6. This article will focus on CMV and EBV, which are associated with the highest rate of hepatic involvement.

\section{Epstein-Barr Virus}

EBV is found worldwide, and nearly 95\% of humans have EBV antibodies by adulthood. Although most widely known for causing infectious mononucleosis, EBV is also associated with Burkitt's lymphoma, Hodgkin's lymphoma, and nasopharyngeal carcinoma, along with central nervous system (CNS) lymphomas in AIDS and posttransplant lymphoproliferative disorders (PTLD) in transplant recipients. ${ }^{1}$

\section{Pathogenesis}

Primary EBV infection is spread by exposure to oral secretions from seropositive persons. Most cases occur through asymptomatic shedding of the virus. After primary infection, EBV remains latent in B cells.

The exact mechanism of EBV-induced hepatitis remains unknown. On histology, acute infectious mononucleosis causes mild portal inflammation, with lymphocyte infiltration of the portal tract and sinusoids. The bile ducts and hepatic arterioles are usually spared. In severe EBV hepatitis, spotty necrosis of the liver parenchyma has been demonstrated. Additionally, in situ hybridization studies have found that EBV remains in $\mathrm{CD}^{+} \mathrm{T}$ lymphocytes that infiltrate the liver; it does not directly invade hepatocytes. ${ }^{2}$

Transplant recipients are at risk for primary EBV infection via latently infected donor B cells that travel with the graft. Reactivation of latent EBV can occur in the setting of immu- nosuppressive medications and the lack of an appropriate $\mathrm{T}$ cell response. Treatment of graft rejection increases the risk of EBV reactivation. Both primary infection and reactivation can lead to uncontrolled proliferation of EBV-infected B lymphocytes, a condition known as PTLD. ${ }^{3}$ Half of all PTLD cases are associated with EBV, and most EBV-related cases occur within the first year of transplantation.

\section{Clinical Manifestations}

Infectious mononucleosis typically presents with fever, sore throat, and lymphadenopathy. Table 1 lists the common signs, symptoms, and hepatic laboratory abnormalities of EBV. ${ }^{1,4}$

PTLD is generally suspected when a transplant recipient has a persistent, unexplained fever, particularly within the first year of transplantation. Common clinical signs and symptoms are summarized in Table 2. Focal lesions can develop in any organ, including the allograft itself. ${ }^{3}$

\section{Diagnosis}

The diagnosis of infectious mononucleosis is based on both clinical manifestations and laboratory testing. Heterophile antibodies are present in up to $90 \%$ of cases, and when positive, it is sufficient to make the diagnosis of EBV. False negative tests can occur in up to $25 \%$ of patients within the first week of illness, however. For a patient with clinical signs of infectious mononucleosis and a negative heterophile antibody, the heterophile antibody test can be repeated a week later. If an exact diagnosis is sought and the heterophile antibody is negative, testing for EBV-specific antibodies, such as anti-viral capsid antigen (VCA) and antiEBV nucleic acid antigen (EBNA), can be performed (Fig. 1). A positive VCA IgM antibody paired with a negative anti-EBNA is highly specific for acute infection.

When PTLD is suspected, radiographic imaging with computed tomography is typically performed to look for

Abbreviations: CMV, cytomegalovirus; EBV, Epstein-Barr virus; PTLD, posttransplant lymphoproliferative disorders; SOT, solid organ transplant.

From the Section of Infectious Diseases, Temple University Hospital, Philadelphia, PA.

Potential conflict of interest: Nothing to report.

View this article online at wileyonlinelibrary.com

(c) 2015 by the American Association for the Study of Liver Diseases

doi: $10.1002 /$ cld. 500 
mass lesions. Brain MRI should be considered for focal neurologic findings or altered mentation. To definitively diagnose PTLD, a biopsy is required. EBV viral loads lack sensitivity and specificity for PTLD; however, higher viral loads have been associated with a higher likelihood of developing PTLD.

\section{Treatment}

Infectious mononucleosis is generally treated with supportive care. Antiviral agents do not reduce symptoms or

TABLE 1 Symptoms, Signs, and Laboratory Abnormalities in Infectious Mononucleosis*

\begin{tabular}{|c|c|c|}
\hline Symptoms & Percentage & Notes \\
\hline Sore Throat & 82 & $\begin{array}{l}\text { Lasts } 7-10 \text { days; } \\
\text { peaks at } 3-5 \text { days }\end{array}$ \\
\hline Malaise & 57 & \\
\hline Headache & 51 & \\
\hline Anorexia & 21 & \\
\hline Nausea & 12 & \\
\hline Abdominal Discomfort & 9 & \\
\hline Signs & Percentage & Notes \\
\hline Lymphadenopathy & 94 & $\begin{array}{l}\text { Anterior and posterior } \\
\text { cervical chains }\end{array}$ \\
\hline Pharyngitis & 84 & \\
\hline Fever & 76 & $\begin{array}{l}\text { Lasts } 10-14 \text { days; highest } \\
\text { in first week }\end{array}$ \\
\hline Splenomegaly & 52 & \\
\hline Hepatomegaly & 12 & \\
\hline Jaundice & 5 & \\
\hline Lab Abnormalities & Percentage & Notes \\
\hline AST and ALT & Up to 90 & $\begin{array}{l}\text { 2-3× ULN; Rise } 2 \text { days after } \\
\text { symptom onset, peak at } \\
8-13 \text { days, and return to } \\
\text { normal around } 20 \text { days }\end{array}$ \\
\hline ALP & 72 & $\begin{array}{l}<2 \times \text { ULN in most cases; } \\
\text { rise within the first few days } \\
\text { of illness, can persist even } \\
30 \text { days after onset }\end{array}$ \\
\hline Bilirubin & 20 & $\begin{array}{l}\text { Typically a mild conjugated } \\
\text { hyperbilirubinemia that } \\
\text { normalizes within } 3 \text { weeks }\end{array}$ \\
\hline
\end{tabular}

AST: Aspartate Aminotransferase; ALT: Alanine Aminotransferase; ALP: Alkaline Phosphatase; ULN: Upper limit of normal et $\mathrm{al}^{4}$

*Adapted from Johannsen EC and Kaye $\mathrm{KM}^{1}$ and Kofteridis EP decrease the duration of disease. No specific treatment exists for EBV hepatitis, though patients have undergone successful liver transplantation for EBV-associated acute liver failure. ${ }^{5}$ Treatment of PTLD generally involves a reduction in transplant immunosuppression. In localized disease, surgical resection and/or radiotherapy can be considered. Rituximab has been used as both adjuvant treatment and prophylaxis of PTLD.

\section{Cytomegalovirus}

CMV affects $30 \%$ to $97 \%$ of individuals worldwide, depending on region, with the highest rates in developing countries. The presentation of CMV varies depending on the status of a patient's immune system. Young, healthy adults with primary CMV infection often present with an infectious mononucleosis syndrome. Profound immunodeficiency caused by human immunodeficiency virus can lead to CNS disease, including retinitis and polyradiculopathy, as well as esophagitis and colitis. Recipients of hematopoietic stem cell transplant (HSCT) and solid organ transplant (SOT) are susceptible to primary infections but can also

TABLE 2 Signs and Symptoms of PTLD*

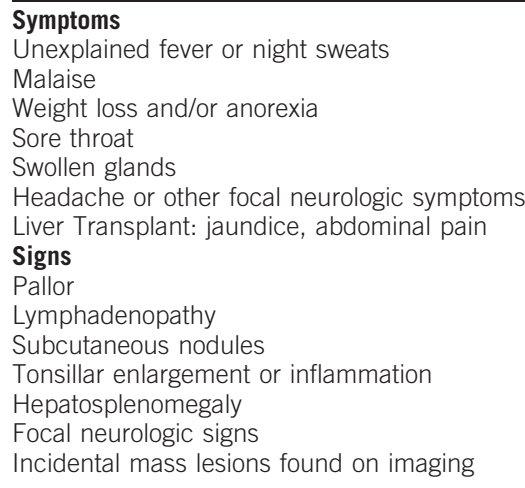

PTLD: Posttransplant lymphoproliferative disorder ${ }^{*}$ Adapted from Green $\mathrm{M}$ and Michaels $\mathrm{MG}^{3}$

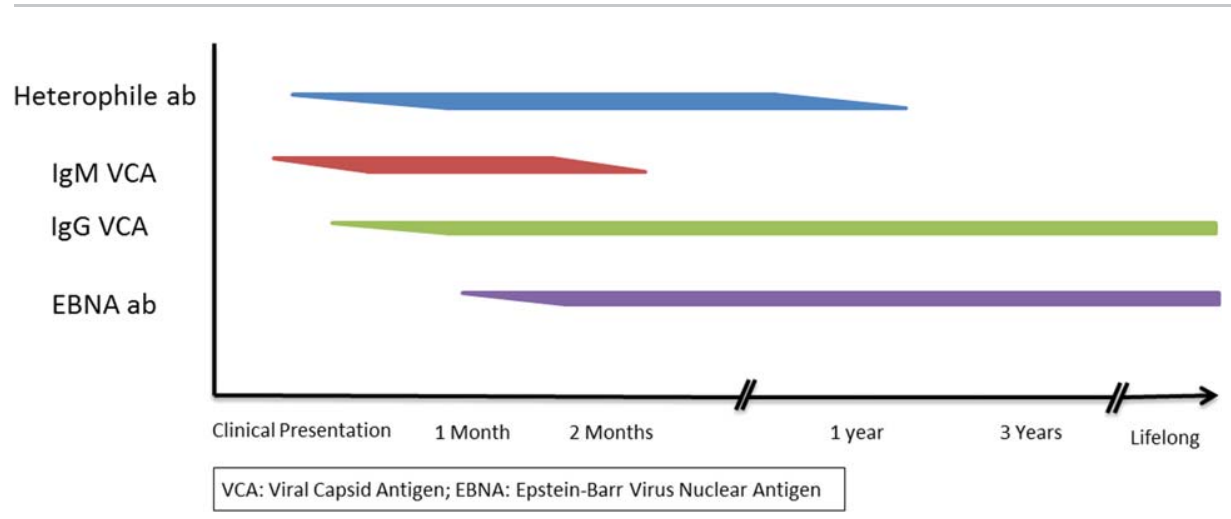

Figure 1 Antibodies to Epstein-Barr Virus 


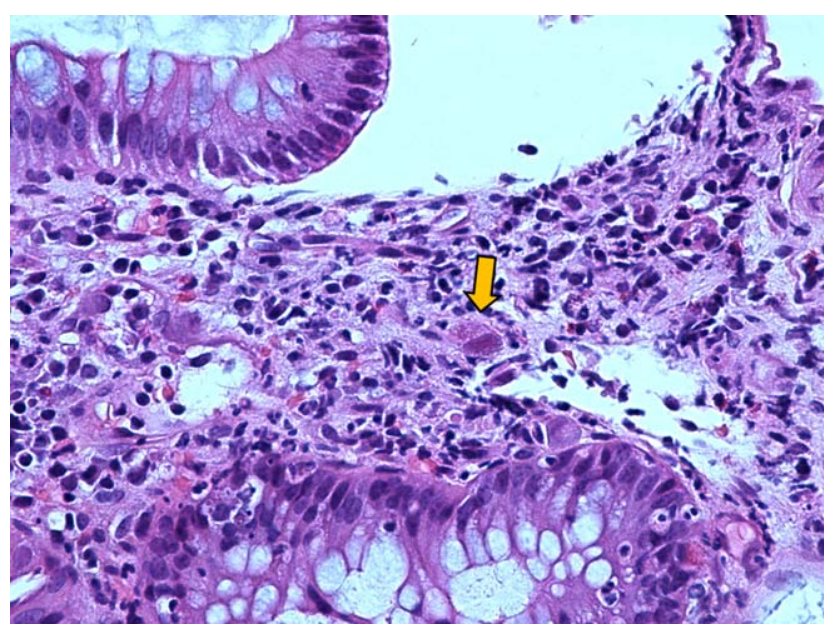

Figure 2 Hematoxylin and eosin staining of colonic tissue from a liver transplant recipient. The orange arrow indicates a giant cell with the characteristic cytoplasmic inclusions (upper left of the cell) and basophilic nuclear inclusions (owl's eye). Image courtesy of Temple University Hospital, Department of Pathology and Laboratory Medicine.

acquire CMV from the donated organ. In addition, reactivation of previously latent CMV occurs in the setting of immunosuppressive medications. ${ }^{6}$

\section{Pathogenesis}

CMV is shed from bodily fluids and commonly enters the body via the alimentary, respiratory, or genitourinary tract. SOT, HSCT, and blood transfusion are also known to transmit $\mathrm{CMV}^{6,7}$ The exact mechanism of CMV transmission to target organs is unknown. Intranuclear CMV inclusions (deemed "owl's eyes" for their appearance on histopathology; Fig. 2) can be found in virtually every organ. In cases of CMV hepatitis, cytomegalic cells are most often found in the bile duct epithelium. Less frequently, they are seen in the capillary epithelium or the liver parenchyma. In liver transplant patients, CMV has been associated with a distinct bile duct sclerosis syndrome. ${ }^{8}$

\section{Clinical Manifestations}

In immunocompetent hosts, CMV infection emulates the clinical presentation of EBV mononucleosis, as shown in Table 3. Liver function abnormalities occur in up to $90 \%$ of cases, but these findings are usually mild and resolve within a few weeks of infection. Nonetheless, cases of severe cholestasis, granulomatous hepatitis, and acute liver failure have been reported. ${ }^{9}$

Transplant recipients present in a variety of ways, depending on the type of organ or graft received. CMV has a predilection to invade the allograft ${ }^{10}$; for example, liver transplant patients are at high risk for CMV hepatitis. CMV infection can present as an asymptomatic viremia, as a viral syndrome with fever, malaise, leukopenia, and thrombocy-
TABLE 3 Comparison of Clinical Characteristics of EBV and CMV Mononucleosis

\begin{tabular}{llc}
\hline Clinical Feature & \multicolumn{1}{c}{ EBV } & CMV \\
\hline Fever & Present & Present \\
Lymphadenopathy & Present & Present \\
Lymphocytosis & Present & Present \\
Atypical Lymphocytes & Present & Present \\
Sore Throat & Often Present & Absent \\
Tonsillar Exudates & Often Present & Absent \\
Heterophile Antibody & Present (90\%) & Absent \\
\hline
\end{tabular}

EBV: Epstein-Barr Virus; CMV: Cytomegalovirus

topenia (typically in primary infection, also called the "CMV syndrome"), or as tissue-invasive disease. Typically, CMV infection develops one to four months after transplant or the discontinuation of CMV prophylaxis. Approximately $10 \%$ of patients undergoing liver transplant will develop CMV hepatitis, and the risk is higher when the donor is CMV-seropositive. CMV hepatitis presents with prolonged fever, hyperbilirubinemia, and elevated hepatic enzymes. ${ }^{6}$

\section{Diagnosis}

Most cases of CMV infection in immunocompetent persons are asymptomatic, so these cases are not detected with laboratory testing. Transplant recipients and their donors are routinely tested for CMV IgG antibodies to help determine the risk for $\mathrm{CMV}$ reactivation. CMV polymerase chain reaction assays have become a mainstay of virus detection, particularly in transplant recipients.

Although CMV viremia in an immunocompromised patient with laboratory or radiographic evidence of tissue involvement can be suggestive of CMV disease, the definitive diagnostic test is a biopsy. ${ }^{6}$ For instance, it is nearly impossible to distinguish between CMV hepatitis and graft rejection without histopathology, but it is important to make the distinction because the treatment differs in terms of both antiviral agents and immunosuppression. In immunocompetent individuals, severe organ dysfunction is uncommon, so biopsy in this patient population is rarely necessary.

\section{Treatment}

CMV mononucleosis affecting immunocompetent patients is self-limiting, and treatment with antivirals is rarely needed. In SOT recipients, CMV disease is usually treated with valganciclovir. Intravenous ganciclovir is favored for severe, lifethreatening illness. Foscarnet and cidofovir are used mainly in the setting of ganciclovir intolerance or resistance. Transplant recipients may require a reduction in immunosuppression in conjunction with antivirals for severe infections. ${ }^{10}$

\section{CORRESPONDENCE}

Heather Clauss, MD, Temple University Hospital, Section of Infectious Diseases, 3401 N. Broad Street, Parkinson Pavilion 5th Floor, Philadelphia, PA. Email:heather.clauss@tuhs.temple.edu, hec22@temple.edu 


\section{References}

1. Johannsen EC, Kaye KM. Epstein-Barr virus (infectious mononucleosis, Epstein-Barr virus-associated malignant diseases, and other diseases). In Mandell, Douglass, and Bennett's Principles and Practice of Infectious Diseases. Philadelphia, PA: Elsevier; 2015. pp 1754-1771.

2. Hara S, Hoshino Y, Naitou T, Nagano K, Iwai M, Suzuki K, et al. Association of virus infected-T cell in severe hepatitis caused by primary Epstein-Barr virus infection. J Clin Virol 2006;35:250-256.

3. Green M, Michaels MG. Epstein-Barr virus infection and posttransplant lymphoproliferative disorder. Am J Transplant 2013;13(suppl 3):41-54.

4. Kofteridis DP, Koulentaki M, Valachis A, Christofaki M, Mazokopakis E, Papazoglou G, et al. Epstein Barr virus hepatitis. Eur J Intern Med 2011;22:73-76.

5. Mellinger JL, Rossaro L, Naugler WE, Nadig SN, Appelman H, Lee WM, et al. Epstein-Barr Virus (EBV) related acute liver failure: a case series from the US Acute Liver Failure Study Group. Dig Dis Sci 2014;59:1630-1637.
6. Crumpacker CS. Cytomegalovirus (CMV). In: Mandell, Douglass, and Bennett's Principles and Practice of Infectious Diseases. Philadelphia, PA: Elsevier; 2015. pp 1738-1753.

7. Ljungman P, Hakki M, Boeckh M. Cytomegalovirus in hematopoietic stem cell transplant recipients. Infect Dis Clin North Am 2010;24:319-337.

8. Landolfo S, Gariglio M, Gribaudo G, Lembo D. The human cytomegalovirus. Pharmacol Ther 2003;98:269-297.

9. Yu YD, Park GC, Park PJ, Choi YI, Hwang S, Song GW, et al. Cytomegalovirus infection-associated fulminant hepatitis in an immunocompetent adult requiring emergency living-donor liver transplantation: report of a case. Surg Today 2013;43:424-428.

10. Humar A, Snydman D; AST Infectious Diseases Community of Practice. Cytomegalovirus in solid-organ transplant recipients. Am J Transplant 2009; 9(suppl 4):S78-S86 